\section{$\underset{\substack{\text { hommes } \\ \text { \& migrations }}}{ }$}

\section{Hommes \& migrations}

Revue française de référence sur les dynamiques

migratoires

1307 | 2014

L'Afrique qualifiée dans la mondialisation

\title{
La diaspora kurde en Europe
}

Dossier proposé par la Représentation du gouvernement régional du Kurdistan-Irak en France

\section{(2) OpenEdition \\ 12 Journals}

\section{Édition électronique}

URL : http://journals.openedition.org/hommesmigrations/2895

DOI : 10.4000/hommesmigrations.2895

ISSN : 2262-3353

Éditeur

Musée national de l'histoire de l'immigration

\section{Édition imprimée}

Date de publication : 1 juillet 2014

Pagination : 133

ISBN : 978-2-919040-28-5

ISSN : $1142-852 X$

Référence électronique

«La diaspora kurde en Europe», Hommes \& migrations [En ligne], 1307 | 2014, mis en ligne le 16 janvier 2015, consulté le 22 septembre 2020. URL : http://journals.openedition.org/hommesmigrations/2895 ; DOI : https://doi.org/10.4000/hommesmigrations.2895 


\section{REPÉRAGE}

\section{LA DIASPORA KURDE EN EUROPE}

Dossier proposé par la REPRÉSENTATION DU GOUVERNEMENT RÉGIONAL

DU KURDISTAN-IRAK EN FRANCE, à qui la revue a donné carte blanche

L'es es Kurdes sont une nation sans État. Suite à l'échec du traité de Sèvres qui prévoyait la création d'un "territoire autonome des Kurdes", les Kurdes sont aujourd'hui principalement répartis sur le territoire de quatre États : la Turquie, l'Irak, la Syrie et l'Iran. La diaspora kurde en Europe est principalement constituée de personnes ayant directement fui des persécutions perpétrées contre elles par les États "dominateurs", surtout dans les années 1970 et 1980.

Cet ensemble d'articles sur la diaspora kurde en Europe met en évidence plusieurs phénomènes et dynamiques qui traversent une communauté diasporique. On observe partout le rôle important de la diaspora dans le développement et la diffusion de la culture. Que ce soit dans le développement d'un "cinéma kurde" à part entière, ou dans celui de la langue kurde, de la littérature, les Kurdes exilés sont très actifs. Ils contribuent également au développement du nationalisme kurde et œuvrent pour le rapprochement de leur peuple divisé sur le territoire de quatre États différents. On peut observer que l'expression artistique est souvent engagée et peut parfois être au service de la lutte politique.

La diaspora kurde joue également un rôle décisif dans la sensibilisation de la communauté internationale à la cause kurde, notamment par le travail de reconnaissance de la campagne de l'Anfal menée en Irak par le régime de Saddam Hussein contre les Kurdes, du massacre d'Halabja, et de sa qualification de génocide. Aujourd'hui, le poids des membres de la diaspora est important au sein du gouvernement régional du Kurdistan-Irak, où beaucoup sont retournés pour occuper des postes à responsabilités, aussi bien au niveau politique et administratif que dans le secteur privé. Leur impulsion joue beaucoup, notamment dans le développement démocratique du Kurdistan. Une problématique qui traverse la population kurde est celle de la "double identité" imposée par l'État dominateur. Dans le cas de l'exil, cette identité devient même triple et transfrontalière. On peut alors observer un affranchissement vis-à-vis du "pays-État" d'origine, où les Kurdes étaient souvent traités comme des citoyens de seconde catégorie, au profit d'un rapprochement de la culture kurde, voire d'une revendication de "kurdicité". On découvre le rôle de la radio, des médias en général, mais aussi des nouvelles technologies et des réseaux sociaux, ou encore du sport, surtout pour la plus jeune génération, dans l'affirmation de l'identité kurde.

Cet ensemble d'articles permet de découvrir la particularité du Kurdistan en matière de diversité culturelle et religieuse, mais aussi les conditions spécifiques d'accueil des réfugiés politiques en Suède, où les Kurdes ont connu un sort à l'opposé de ce qu'ils vivaient dans leur pays d'origine : ils y jouissent de droits et de libertés jamais (re) connus. Au-delà de l'actualité dramatique récente au Moyen-Orient dominée de nouveau par le sort terrible réservé aux minorités, il s'agit d'écrire l'histoire toute particulière de l'arrivée en France de réfugiés kurdes irakiens en 1989, commémorée par la Représentation du Kurdistan-Irak en France à travers l'exposition itinérante Kurdes d'Auvergne, Français d'ailleurs, qui revient sur la question fondamentale des valeurs universelles de liberté, de fraternité et d'égalité. I 